\title{
Study on the Quality Management and Control of Water and Soil Conservation Engineering
}

\author{
Daoming, Cai ${ }^{1, \mathrm{~A}^{*}}$ and Bo, $\mathrm{Hu}^{2, \mathrm{~b}}$ \\ ${ }^{1.2}$ Department of Soil and Water Conservation, Changjiang River Scientific Research Institute, \\ Hubei province, 430010, China \\ acdm1528@126.com, bcdmchina1983@hotmail.com
}

Keywords: Water and Soil Conservation Engineering; Quality Management; Control Study

\begin{abstract}
In order to keep sustainable development, water and soil conservation engineering is essential. Since the reform and opening-up, China has developed in various aspects, while water and soil conservation engineering is no exception. However, its development is valued comparing to the history. There is still a large gap between China and developed countries in terms of its quality management as well as water and soil conservation engineering. Therefore, according to the real condition, it is of pivotal importance to strengthen the study on the management and control of water and soil conservation engineering. This paper briefly describes the necessity, importance of water and soil conservation engineering, hoping to guarantee the smooth and feasible implementation.
\end{abstract}

\section{Introduction}

So-called water and soil conservation engineering aims to prevent loss of water and soil erosion; protect and reasonably take advantage of the resources of mountain area, rolling terrain and windy dust area; protect and improve the sustainable productive ability of soil and water. In addition, it expects to reach the maximum economic and social benefits of soil and water to build a good and recyclable ecological environment project. It is known to all that, even though some resources are sustainable, the requirement of resources is soaring because of the extreme increase of human beings and excessive exploitation and utilization have already caused irreparable loss. At this time, the government needs water and soil conservation engineering to take macro-control on the resources. Water and soil engineering management is an important branch of water and soil engineering. However, in current water and soil engineering management, there are lots of shortcomings. For example, there is a phenomenon of lack of management and good control. As a result, it is insufficient and wastes lots of resources. We should start from the root to regulate the water and soil conservation engineering from the perspective of system and mechanism so as to strengthen the ecological construction, to thus improve its investment value. So, we have to establish a sound regulation and supervision management system conforming to water and soil engineering conservation, so as to improve the quality management ability and administration ability in all aspects.

\section{The Importance of Water and Soil Conservation Engineering}

China is a vast country with rich resources reservations. However, from the current water and soil condition, we cannot predict a good future. Lots of rivers and lakes in China have suffered from soil and water loss in different levels. For example, Loess Plateau Areas of Northwest China covering from Haikou Town of Inner Mongolia to Longman of Shanxi, have the worst condition in terms of water and soil loss. Water and soil erosion will definitely cause great harm on the ecological environment, production as well as life and economic development of local areas and lower reaches of river; in addition, it will also destroy the integrity of land, cause soil fertility decrease and contribute to land putrescence desertification. Based on this, all of the above will threaten the safety of agricultural production and towns; aggravate drought and appearance of natural disaster and the sustainable development of life, economy and the society as a whole. It is because the water and 
soil conservation engineering is closely related to the living condition and lasting political stability of people that we have to focus on the importance of water and soil conservation engineering. In addition, the quality management is of significant importance to the areas depending on water and soil conservation.

\section{Quality Management of Water and Soil Conservation Engineering}

Importance of the Quality Management of Water and Soil Conservation Engineering. The construction of an engineering project cannot be divorced from management and water and soil conservation engineering is no exception. When we carry out a project, we have to pay $30 \%$ of our focus on construction while $70 \%$ of our focus on management, which is a truth and whether the quality management goal can be accomplished or not will directly affect the final result of water and soil conservation engineering. We should set a feasible target and work toward it. Therefore, the quality management of water and soil conservation engineering is of pivotal importance.

Water and Soil Conservation Engineering Quality Management Analysis. Water and soil conservation engineering management can be generally divided into two parts: the first one is water and soil protection facilities, which should be monitored by water and soil conservation engineering regulatory bodies and they should act based on relative laws and punish those who destroy the water and soil conservation engineering facilities; secondly, concerning water and soil conservation engineering, it covers maintenance, reform, updating. Generally, we have to pay attention to the second aspects. As far as we are concerned, to carry out contract, auction, and lease are transitions to keep water and soil management, which cannot be considered as a perfect plan. A real perfect plan should take water and soil engineering as fixed assets, including register, maintain and keep the water and soil resources. In addition, water and soil engineering needs special institutions, technical staffs and funds as bases. For example, after the completion of water conservancy project, we have to hand it to water engineering management unit; after the completion of afforestation carried out by forestry department, the forestry center is supposed to manage with administrative expenses; after the road construction, management should also be carried out while charging toll fees to regularly maintain the roads. However, at present, after the water and soil engineering project being carried, there is not an institution in charge of managing, so lots of problems will emerge and no one will take the responsibility. If things continue this way, it will affect the water and soil conservation engineering development in a negative way. Water and soil conservation engineering is a project integrating social and economic benefits, which cannot be ignored.

Problems and Effects of Water and Soil Conservation Engineering Quality Management. To begin with, the water and soil conservation engineering project has lots of problems, and the main problems are that the management is not perfect. Generally, relative enterprises will be interested in construction with handsome funds. However, after the completion of project, there are lots of problems in management such as lack of funds and running out of money. Even though, the government will invest a lot in water and soil conservation engineering, the funds are still inadequate. Because of this, advanced equipment cannot be applied. Therefore, the government should implement macro-control, increase funds investment, carry out effective financing to create enough capital for maintenance and purchasing advanced equipment. Based on this, we can fully play its function. Another case is relative departments and units do not pay attention to management. As is known to all, water and soil conservation is a kind of comprehensive management, which is complicated and difficult. If all the funds are invested on construction, the environment will be improved yet it cannot be kept for a long time. What will do good to sustainably develop water and soil engineering will be related to a series of management work. Enterprises and the society do not pay enough attention to the management work, which is not supported by relative regulations, and therefore, there are loopholes in water and soil conservation engineering projects.

What's more, the water and soil management work lags behind. After the completion of water and soil engineering projects, the management as well as maintaining work is not charged by the government or relative departments but township collectives or even individual, who do not have clear regulations nor perfect management solutions. Based on this, water and soil conservation 
engineering cannot be timely maintained and managed, even though there are institutions of water and soil institutions, the management work cannot be implemented well because of lack of management fee for a long time.

Furthermore, the understandings toward water and soil management work are shallow while the quality of some employees is not good and some misunderstandings will lead to mistakes. For example, the project which needs permanent management becomes a temporary project. For example, we can conclude that the management mode of lease and contract is not perfect and some projects are not well managed. To hand the management right to the operators can work temporarily which yet cannot help us to achieve the goals. In order to keep the value of water and soil conservation engineering, we have to carry out a new study on our management work.

Affects are showing in the following if we do not focus on the water and soil conservation engineering: because the management system of water and soil conservation engineering is not perfect and we cannot implement the management well, and because of the lack of management fees, the water and soil engineering cannot be well managed and its effect is not obvious. After the completion of a water and soil engineering project, it is the best time to get the efficiency, yet as time passes by, the project of water and soil cannot play well because of lack of management and human behavior. As a result, there is soil erosion and the areas which need to be managed will expand. Under such circumstance, the government will reconstruct, which will inevitably lead to resources waste. If we cannot solve the problems from the root, we will have a vicious circle, such as we build in the first year, and it cannot play well in the second year, which is still the same the third year. It does not only waste money and manpower, but also cannot solve the problem of water and soil erosion.

\section{Plans to Strengthen the Quality Management of Water and Soil Conservation Engineering}

In order to further perfect the water and soil conservation engineering, we have to make relative quality management measures so as to ensure the overall result.

Combine the quality management of water and soil conservation engineering to other management mechanisms. The quality management of government water and soil can refer to the excellent management of other industries, such as agriculture, and forest. After a completion of a project, we have to hand the management right to other relative departments so as to keep the water and soil engineering into fixed assets, which is beneficial to keep the value so as to have more benefits and can be directly used in daily maintenance and purchasing new equipment.

Introduce the management fee into budget of maintaining water and soil conservation engineering. In the budget of water and soil conservation, we can regulate different management fees based on the nature, function, which is similar to the raising fees and management fees of forest and it can guarantee the endurance power to keep a guarantee the water and soil conservation engineering.

\section{Strengthen the Law Regulations during Various Sections of Water and Soil Conservation Engineering So As To Make There Are Laws to Abide By}

Laws and regulations will contribute a lot to the effective implementation of some measures, which cannot manage but also act as an obligatory role to punish irresponsible actions. It will create invisible pressure so that people will take the initiative to work. On another hand, some laws related to water and soil conservation is being modified, and we have to make it clear about responsible units and management budgets so as to avoid loopholes.

All in all, water and soil conservation is closely related to economic lifelines and people's live and work in peace and contentment. To perfectly keep the water and soil conservation engineering cannot only ensure the life condition of residents living along the rivers but also guarantee the prevention and treatment of natural disasters. Therefore, in order to keep the quality of water and soil conservation engineering, relative departments should keep the original quality management system. By improving the quality management system, relative departments will help each other 
and the responsibilities are clearly defined. Based on these, they will implement their responsibilities and mutually help each other.

\section{Conclusion}

In the society with rapid development, people are paying soaring attention to water and soil conservation engineering. What's more, we should take its management as a subject and highlight its function. Based on this, some departments should clear various problems at present and come up with ideas to solve them. Moreover, relative departments in terms of water and soil conservation engineering should also help each other and coordinate to avoid the situation that no one is going to manage. The main purpose of water and soil conservation engineering is to protect the environment and maintain the balance of ecology. Therefore, we have to perfect the water and soil conservation engineering to contribute ourselves to create a beautiful planet rather than taking this planet for granted.

\section{Acknowledgements}

Projects to promote science and technology from Ministry of Water Resources (NO.TG1518)

T.D. Zhang, A.J. Shih and E. Levin: Annals of the CIRP, Vol. 43 (1994) No.3, p.305.

\section{References}

[1] G.L. Wang: Test Report, Vol. 67 (2013), p.195-196.

[2] J.L. Ju: China High Technology Enterprises, Vol. 3 (2016), p.280-283.

[3] C.S. Qi: Hebei Water Resources, Vol. 12 (2015), p.42.

[4] T.L. Qi: Technology Innovation and Application, Vol. 09 (2016), p.207.

[5] G.R. Xiao:Guirong, Discuss on the Measures for Environmental Protection and Soil and Water Conservation along Railway(Southwest Jiao tong University 2011). p48.

[6] J.Y. Chen: Comprehensive Control Mode for the North Areas of Weihe River of Shanxi Province in Hanyuan Qinzhuang Gully (Shaanxi Normal University, China 2014), p53.

[7] A. Li: Henan Water Resources \& South-to-North Water Diversion, Vol. 12 (2012), p. 163-164.

[8] Y.S. Tang:Soil and Water Conversation in China, Vol. 08 (2010), p58-59.

[9] D. Li: Comprehensive Control Mode for the Water and Soil Conservation Engineering of Upper and Middle Yellow River (Hohai University 2006), p60.

[10]H. Huang and H.F. Chen:Beijing Agriculture, Vol. 15 (2014), p247-248. 